\title{
Sensory Neuron Signaling to the Brain: Properties of Transmitter Release from Olfactory Nerve Terminals
}

\author{
Gabe J. Murphy, Lindsey L. Glickfeld, Zev Balsen, and Jeffry S. Isaacson \\ Neuroscience Graduate Program and Department of Neuroscience, University of California, San Diego School of Medicine, La Jolla, California 92093-0608
}

Olfactory receptor neurons (ORNs) convey sensory information directly to the CNS via conventional glutamatergic synaptic contacts in olfactory bulb glomeruli. To better understand the process by which information contained in the odorant-evoked firing of ORNs is transmitted to the brain, we examined the properties of glutamate release from olfactory nerve $(\mathrm{ON})$ terminals in slices of the rat olfactory bulb. We show that marked paired pulse depression is the same in simultaneously recorded periglomerular and tufted neurons, and that this form of short-term plasticity is attributable to a reduction of glutamate release from $\mathrm{ON}$ terminals. We used the progressive blockade of NMDA receptor (NMDAR) EPSCs by MK-801 [(5R,10S)-(+)-5-methyl-10,11-dihydro-5H-dibenzo[a,d]cyclohepten-5-10-imine hydrogen maleate] and stationary fluctuation analysis of AMPA receptor (AMPAR) EPSCs to determine the probability of release $\left(\mathrm{P}_{\mathrm{r}}\right)$ of $\mathrm{ON}$ terminals; both approaches indicated that $\mathrm{P}_{\mathrm{r}}$ is unusually high $(\geq 0.8)$. The low-affinity glutamate receptor antagonists $\gamma$-Dglutamylglycine and L-amino-5-phosphonovaleric acid blocked ON-evoked AMPAR- and NMDAR-mediated EPSCs, respectively, to the same extent under conditions of low and high $\mathrm{P}_{\mathrm{r}}$, suggesting that multivesicular release is not a feature of $\mathrm{ON}$ terminals. Although release from most synapses exhibits a highly nonlinear dependence on extracellular $\mathrm{Ca}^{2+}$, we find that the relationship between glutamate release and extracellular $\mathrm{Ca}^{2+}$ at $\mathrm{ON}$ terminals is nearly linear. Our results suggest that $\mathrm{ON}$ terminals have specialized features that may contribute to the reliable transmission of sensory information from nose to brain.

Key words: MK-801; olfactory bulb; glutamate; release probability; paired pulse depression; calcium; multivesicular release

\section{Introduction}

Olfaction begins in the olfactory epithelium, where odorants bind G-protein-coupled receptors on the dendritic cilia of olfactory receptor neurons (ORNs) (Firestein, 2001). Receptor activation initiates a cascade of events that leads to the opening of cyclic nucleotide-gated channels and membrane depolarization (Nakamura and Gold, 1987). Activity in ORNs is conveyed directly to the brain via olfactory nerve $(\mathrm{ON})$ input to the olfactory bulb. Here, $\mathrm{ON}$ terminals make excitatory glutamatergic synapses onto the dendrites of principal mitral and tufted (M/T) cells and local interneurons, periglomerular (PG) cells, in olfactory bulb glomeruli.

Recent evidence suggests that individual ORNs express only one of $\sim 1000$ possible odorant receptors (Chess et al., 1994; Serizawa et al., 2000, 2003). ORNs that express the same odorant receptor send their axons to the same olfactory bulb glomeruli (Mombaerts et al., 1996). These findings, and imaging of glomerular activity in vivo (Rubin and Katz, 1999; Wachowiak and Cohen, 2001), have suggested that odorant identity is encoded by spatial patterns of activity in the bulb (Mori et al., 1999). Alter-

Received Dec. 30, 2003; revised Feb. 10, 2003; accepted Feb. 10, 2003.

This work was supported by National Institute on Deafness and Other Communication Disorders (NIDCD) National Research Service Award Predoctoral Fellowship DC005679 (G.J.M.), Burroughs Wellcome Fund Career Award, McKnight Scholar Award, Klingenstein Award, and NIDCD Grant R01 DC04682 (J.S.I.), and L.L.G. is a Merck Fellow. We thank Massimo Scanziani for helpful discussions and Kevin Franks for comments on this manuscript.

Correspondence should be addressed to Dr. Jeffry S. Isaacson, Basic Science Building, Room 3065, University of California, San Diego, School of Medicine, 9500 Gilman Drive, La Jolla, CA 92093-0608. E-mail: jisaacson@ucsd.edu. DOI:10.1523/JNEUROSCI.5745-03.2004

Copyright $\odot 2004$ Society for Neuroscience $\quad$ 0270-6474/04/243023-08\$15.00/0 natively, it has been proposed that information about the identity and concentration of odorants can be encoded in the timevarying activity of neurons in the olfactory system (Stopfer et al., 1997, 2003).

Regardless of the ultimate coding strategies used for olfaction, the properties of synaptic transmission between ORNs and their postsynaptic targets in the olfactory bulb will constrain how olfactory stimuli are encoded in the brain. In the sensory systems underlying vision and audition, sensory neurons have particular properties that ensure faithful transmission of information from the outside world to the brain. Sensory neurons in the retina and cochlea, for example, have presynaptic specializations called "synaptic ribbons." Ribbon synapses enable sustained transmitter exocytosis (Lenzi and von Gersdorff, 2001) and are believed to contribute to the high fidelity transmission of sensory information (Juusola et al., 1996; Laughlin et al., 1998). In contrast to these unusual anatomical specializations, ORNs appear to have rather conventional nerve endings in the olfactory bulb (Pinching and Powell, 1971; White, 1972, 1973). Do the synapses of ORNs in the olfactory bulb also possess features that enable information about sensory stimuli to be passed efficiently from receptor neurons to the CNS?

To better understand how olfactory information is transmitted to the brain, we examined the intrinsic features of synaptic transmission between ORNs and their synaptic targets in the olfactory bulb. We found that ORN synapses show marked paired pulse depression (PPD), and that this short-term plasticity is mediated presynaptically. We used several independent approaches 
to estimate the probability of release $\left(\mathrm{P}_{\mathrm{r}}\right)$ from $\mathrm{ON}$ terminals and found that the $\mathrm{P}_{\mathrm{r}}$ is unusually high $(\geq 0.8)$. The glutamate concentration at ORN synapses does not change when $\mathrm{P}_{\mathrm{r}}$ is lowered, indicating that multivesicular release does not contribute to the peak amplitude of synaptic responses. We also demonstrate that glutamate release from these synaptic terminals is not as steeply dependent on extracellular $\mathrm{Ca}^{2+}$ as most other central synapses. Together, these results suggest that the olfactory system has developed unusual features of synaptic signaling to transmit olfactory information to the brain.

\section{Materials and Methods}

Slice preparation and electrophysiology. Olfactory bulb and piriform cortex slices $(\sim 300 \mu \mathrm{m})$ were prepared from 2 - to 4 -week-old Sprague Dawley rats in accordance with institutional and national guidelines using standard procedures. Slices were maintained in artificial CSF (aCSF) containing (in mM): $83 \mathrm{NaCl}, 2.5 \mathrm{KCl}, 3.3 \mathrm{MgSO}_{4}, 1 \mathrm{NaH}_{2} \mathrm{PO}_{4}, 26.2$ $\mathrm{NaHCO}_{3}, 22$ glucose, 72 sucrose, and $0.5 \mathrm{CaCl}_{2}$, and equilibrated with $95 \% \mathrm{O}_{2} / 5 \% \mathrm{CO}_{2}$ at $34^{\circ} \mathrm{C}$ for $30 \mathrm{~min}$ and at room temperature thereafter. In the recording chamber, slices were viewed via infared differential interference contrast optics (BX-51W1; Olympus Optical, Melville, NY) and superfused with aCSF containing (in $\mathrm{mM}$ ): $119 \mathrm{NaCl}, 2.5 \mathrm{KCl}, 1.3$ $\mathrm{MgSO}_{4}, 1 \mathrm{NaH}_{2} \mathrm{PO}_{4}, 26.2 \mathrm{NaHCO}_{3}, 22$ glucose, and $2.5 \mathrm{CaCl}_{2}$. Extra $\mathrm{Mg}^{2+}$ was added to aCSF containing reduced $\mathrm{Ca}^{2+}$ to maintain a constant concentration of divalent ions between conditions.

Whole-cell patch-clamp electrodes $(\sim 3 \mathrm{M} \Omega)$ were pulled from thin wall borosilicate glass and filled with a solution containing (in $\mathrm{mM}$ ): 135 D-gluconic acid, $135 \mathrm{CsOH}, 5 \mathrm{NaCl}, 10$ HEPES, 12 phosphocreatine, 0.2-0.5 EGTA, 3 Mg-ATP, and 0.2 Na-GTP, pH 7.35, 300 mOsm. In experiments examining NMDA receptor (NMDAR)-mediated responses, the internal solution contained $10 \mathrm{~mm}$ EGTA. Series resistance for whole-cell recordings was typically $<10 \mathrm{M} \Omega$ and routinely compensated electronically by $\geq 90 \%$; the uncorrected liquid junction potential in these recordings was $\sim 12 \mathrm{mV}$. Synaptic currents and field potentials were recorded with an Axopatch 200B amplifier (Axon Instruments, Foster City, CA), filtered at $2-5 \mathrm{KHz}$, and collected and digitized at $10-20$ $\mathrm{KHz}$ (ITC-18; InstruTech, Mineola, NY). Data acquisition and analysis were performed with Axograph 4.9 (Axon Instruments) and IGOR Pro 4 (Wavemetrics, Lake Oswego, OR) software. EPSCs and glomerular field EPSPs (fEPSPs) were evoked $(0.05-0.13 \mathrm{~Hz})$ via a bipolar electrode placed in the ON layer; fEPSPs in olfactory cortex were evoked via a bipolar electrode placed in the lateral olfactory tract (LOT). Experiments in the olfactory bulb were performed in the presence of sulpiride $(100 \mu \mathrm{M})$ and (2S)-3-\{[(1S)-1-(3,4-Dichlorophenyl)ethyl $]$ amino-2hydroxypropyl) $\}$ (phenylmethyl)phosphinic acid (CGP 55845; $5 \mu \mathrm{M}$ ) to block presynaptic $\mathrm{D} 2$ and $\mathrm{GABA}_{\mathrm{B}}$ receptors, respectively. Voltage-clamp experiments were performed in the presence of the $\mathrm{GABA}_{\mathrm{A}}$ receptor antagonist picrotoxin $(100 \mu \mathrm{M})$ at $31-34^{\circ} \mathrm{C}$ unless otherwise noted; fEPSP recordings were performed at room temperature. Chemicals were purchased from Fisher Scientific (Fair Lawn, NJ); drugs were obtained from either Sigma-Aldrich (St. Louis, MO) [1,2,3,4-tetrahydro-6-nitro2,3-dioxo-benzo[f] quinoxaline-7-sulfonamide (NBQX), picrotoxin, and sulpiride] or Tocris Cookson (Ellisville, MO) (MK-801 [(+)-5methyl-10,11-dihydro-5H-dibenzo [a,d] cyclohepten-5,10-imine maleate)], L-amino-5-phosphonovaleric acid (L-APV), $\gamma$-D-Glutamylglycine ( $\gamma$-DGG), and CGP 55845).

Data analysis. The amplitudes of EPSCs and fEPSPs were measured over a $0.5-1 \mathrm{msec}$ window centered at the peak of the response. When EPSCs were evoked in rapid (5-100 msec) succession, the amplitude of the second EPSC was determined by subtracting the average response to a single stimulus from that evoked by paired pulse stimulation.

An estimate of the probability of release was obtained by analyzing the rate at which the open channel NMDAR blocker MK-801 inhibited olfactory nerve-evoked NMDAR EPSCs (Hessler et al., 1993; Rosenmund et al., 1993). Stable ON-evoked NMDAR EPSCs were recorded at +40 $\mathrm{mV}$; nerve stimulation was stopped, and MK-801 (40 $\mu \mathrm{M})$ was bath applied. After $4 \mathrm{~min}$, ON stimulation was resumed and the rate of progressive block measured. The blocking rate (Kobl) of $40 \mu \mathrm{M}$ MK-801 was derived from kinetic modeling of NMDAR EPSCs under control conditions and in the presence of the drug. The reaction scheme used to model synaptic NMDAR responses was:

$$
\begin{gathered}
\mathrm{UB} \underset{\mathrm{Kbu}}{\stackrel{2 \mathrm{Kub}}{\rightleftharpoons}} \mathrm{SB} \underset{2 \mathrm{Kbu}}{\stackrel{\text { Kub }}{\rightleftharpoons}} \mathrm{DB} \underset{\mathrm{Kdb}}{\stackrel{\text { Kbo }}{\rightleftharpoons} \text { Open }} \underset{\text { Kob }}{\rightleftharpoons} \text { Kbd } \\
\text { Desen }
\end{gathered}
$$

where UB indicates unbound, SB indicates single bound, DB indicates double bound, and Desen indicates desensitized (Hessler et al., 1993). In each case, the forward rate is above the arrow, and the backward rate is below. For simulations, a brief $(1 \mathrm{msec})$ pulse of glutamate $(1 \mathrm{~mm})$ was delivered, and model parameters were optimized using a least squares fitting procedure in Axograph 4.9. Glutamate binding rate (Kub) was fixed to a value of $5 \mu \mathrm{M}^{-1} \mathrm{sec}^{-1}$. Under control conditions, the blocking rate was set to 0 , whereas all other parameters were free. In each cell, the optimum parameters from control responses were used to fit the response in MK-801 to determine blocking rate. On average, Kbu (unbinding rate $)=17.7 \pm 7.3, \mathrm{Kbo}($ opening rate $)=73.9 \pm 15.8, \mathrm{Kob}($ closing rate $)=90.6 \pm 14, \mathrm{Kbd}($ desensitization rate $)=12.6 \pm 5.9, \mathrm{Kdb}($ resensitization rate $)=11.3 \pm 4.1$, and $\mathrm{Kobl}=37.2 \pm 5.5(n=12)$. Units for all rate constants, other than Kub, are $\sec ^{-1}$. On average, $P_{\text {open }}=0.45 \pm$ 0.07 . This value is higher than in previous studies (Jahr, 1992) and likely reflects differences in the temperature and membrane potential in these recordings.

Nonstationary fluctuation analysis of evoked EPSCs (Clements and Silver, 2000) involved computing the variance of $>20$ consecutive EPSCs under control conditions. $\mathrm{P}_{\mathrm{r}}$ was then reduced, either by lowering extracellular $\mathrm{Ca}^{2+}$ or adding the $\mathrm{Ca}^{2+}$ channel blocker $\mathrm{Cd}^{2+}$, and the mean and variance were measured when the response stabilized. This process was iterated three to four times in each stable cell. Fits to the relationship between EPSC variance and mean amplitude were calculated with the equation $y=A x-B x^{2}$, where $y$ is EPSC variance, and $x$ is mean EPSC amplitude. $A$ and $B$ are used to calculate quantal amplitude $(\mathrm{Q})$ and $\mathrm{P}_{\mathrm{r}}$ according to the equations $Q=A /\left(1+\right.$ c.v $\left._{\text {intra }}{ }^{2}\right)$ and $\mathrm{P}_{\mathrm{r}}=x(B / A)(1+$ c.v.intra $\left.{ }^{2}\right)$, respectively. Parabolic fits and the values of quantal size and $\mathrm{P}_{\mathrm{r}}$ derived from them assumed intrasite quantal variability of 0.3 .

The stability of extracellular field recordings enabled us to vary the concentration of extracellular $\mathrm{Ca}^{2+}$ multiple times within a single experiment to examine the relationship between $\mathrm{Ca}^{2+}$ and glutamate release. In general, experiments began in normal aCSF. After establishing a stable response, the slice was superfused with aCSF with no added $\mathrm{Ca}^{2+}$ for $\sim 10 \mathrm{~min}$. The amount of extracellular $\mathrm{Ca}^{2+}$ was then increased iteratively, and the size of the synaptic response was calculated at each concentration. In experiments where transmission was assayed by measuring the amplitude of ON-evoked EPSCs, a stable baseline response was established in normal aCSF and then in the presence of aCSF with a reduced concentration of extracellular $\mathrm{Ca}^{2+}$. Only experiments in which the response recovered to $\geq 90 \%$ of control after washing back normal aCSF were included in these analyses. The relationship between normalized synaptic response and extracellular $\mathrm{Ca}^{2+}$ was fit with the Hill equation:

$$
\mathrm{EPSC}=\mathrm{EPSC}_{\max }\left(\mathrm{Ca}_{e}{ }^{n} /\left(\mathrm{Ca}_{e}{ }^{n+} K_{0.5}{ }^{n}\right)\right.
$$

$K_{0.5}$ is the concentration of calcium that yielded a half-maximal response, and $n$ is the Hill cooperativity coefficient. The average Hill coefficient derived from individual experiments in which at least four $\mathrm{Ca}^{2+}$ concentrations were tested was $2.03 \pm 0.17(n=4)$. This value is close to the Hill coefficient obtained from the fit to the pooled data set.

Representative traces are the average of five or more consecutive episodes, except where noted. In most cases, the stimulus artifact has been digitally subtracted. All summary data are presented as mean \pm SEM. The Student's $t$ test was used to determine statistical significance. 


\section{Results}

Olfactory receptor neuron axons form glutamatergic synaptic contacts on the dendrites of principal M/T cells and PG interneurons in olfactory bulb glomeruli (Pinching and Powell, 1971). We first examined the nature of paired pulse plasticity at these $\mathrm{ON}$ terminals. Previous studies indicate that paired pulse stimulation of the ON layer produces PPD of glutamate receptor-mediated EPSCs in both M/T and PG neurons (Aroniadou-Anderjaska et al., 2000; Ennis et al., 2001; Murphy and Isaacson, 2003). However, the specific contributions of presynaptic versus postsynaptic mechanisms to this form of short-term plasticity are unclear. We first asked whether the degree of PPD depended on the identity of the postsynaptic cell. To address this question, we made simultaneous voltage-clamp recordings $\left(V_{m}=-70 \mathrm{mV}\right)$ of $\mathrm{ON}$ evoked EPSCs from visualized PG and tufted cells that appeared to project dendrites to the same glomerulus. ON stimulation evoked fast EPSCs in both cell types that were abolished by the AMPA receptor (AMPAR) antagonist NBQX (10 $\mu \mathrm{M}$; data not shown). We measured the paired pulse ratio (PPR; $\mathrm{EPSC}_{2} /$ EPSC $_{1}$ ) of AMPAR-mediated EPSCs in simultaneously recorded $\mathrm{PG}$ and tufted neurons evoked by $\mathrm{ON}$ stimulation over a range of interstimulus intervals (ISIs; $5-1000 \mathrm{msec}$ ). Paired pulse stimulation caused marked PPD that recovered with a monotonic time course, and the magnitude of PPD was identical at all interstimulus intervals examined in the two cell types $(p>0.2 ; n=7$ pairs $)$ (Fig. 1A). These results rule out the possibility that this form of short-term plasticity depends on the postsynaptic target and suggest that PPD is an intrinsic feature of olfactory nerve terminals.

PPD could be a consequence of changes in the amount of neurotransmitter release or reduced sensitivity of AMPARs to synaptically released glutamate. To test the possibility that AMPAR desensitization contributes to PPD, we applied cyclothiazide to block AMPAR desensitization (Vyklicky et al., 1991; Yamada and Tang, 1993). Cyclothiazide (100-200 $\mu \mathrm{M}$; CTZ) slowed the kinetics and increased the amplitude of ON-evoked EPSCs in PG cells (Fig. $1 B_{1}$ ) but did not change the PPR (Fig. $1 B_{2}$ ). This result suggests that receptor desensitization does not underlie the marked PPD of AMPAR-mediated transmission at ON synapses. However, in addition to inhibiting AMPAR desensitization, cyclothiazide has been reported to alter transmitter release at some synapses through a presynaptic mechanism (Diamond and Jahr, 1995; Bellingham and Walmsley, 1999). To further probe whether postsynaptic mechanisms contribute to PPD, we next compared the PPR of AMPAR- and NMDAR-mediated EPSCs in the same PG cells. Although it has been shown that the AMPA and NMDA component of EPSCs can change to the same extent when $P_{r}$ is altered (Perkel and Nicoll, 1993), some studies have found that the PPR of AMPA- and NMDAR-mediated EPSCs can differ because of relative differences in the degree of saturation or desensitization of the two types of glutamate receptors (Mennerick and Zorumski, 1996; Chen et al., 2002). We found that the PPR of AMPAR-mediated responses recorded at $-70 \mathrm{mV}$ was not significantly different from that of NMDAR-mediated EPSCs recorded at $+50 \mathrm{mV}$ in the presence of the AMPAR antagonist NBQX $(10 \mu \mathrm{M})$ (Fig. 1C). Together, these data support the notion that postsynaptic factors do not contribute to PPD at ON terminals.

To further address the locus of PPD, we examined the trialto-trial variability of AMPAR EPSCs evoked by paired pulse stimulation. On average, EPSCs evoked by the first stimulus exhibited significantly less variance than those evoked by the second stimulus (Fig. $1 D_{1}$ ). To determine whether this difference in variabil-
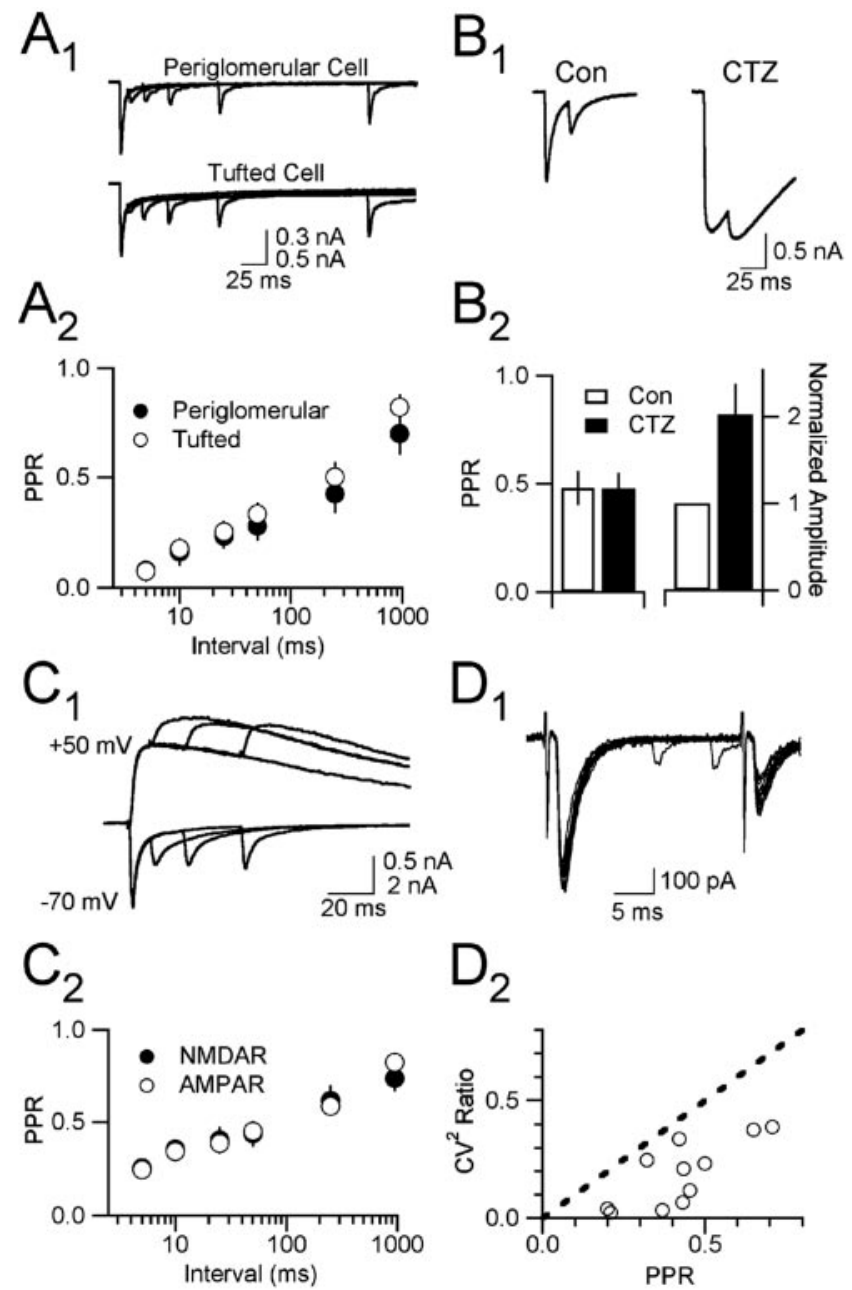

Figure 1. ON terminals show strong presynaptic paired pulse depression. $A_{1}$, The average response of a simultaneously recorded $P G$ and tufted cell to $5,10,25$, and 50 msec paired pulse stimulation. $A_{2}$, Average PPR (EPSC 2 /EPSC $)_{1}$ ) over a range of interstimulus intervals ( $n=7$ pairs). $B_{1}, 0 \mathrm{~N}$-evoked EPSC ( $V_{h}=-70 \mathrm{mV}$ ) before (Con) and after (CTZ) application of cyclothiazide (100 $\mu \mathrm{m}$ ). $B_{2}$, Average effect of CTZ on PPR (left axis) and EPSC $C_{1}$ amplitude (right axis; $n=5) . C_{1}$, AMPAR- and NMDAR-mediated paired pulse depression in a representative PG neuron. $C_{2}$, Average AMPAR- and NMDAR-mediated PPR are not significantly different $(n=7$ cells; $p>0.2$ ). $D_{1}$, Fifteen consecutive AMPAR-mediated responses in a $P G$ neuron evoked by paired pulse stimulation of the $0 \mathrm{~N}$ layer. $\mathrm{D}_{2}, \mathrm{CV}^{2}$ ratio (EPSC $\mathrm{CV}^{2} / \mathrm{EPSC}_{2} \mathrm{CV}^{2}$ ) versus PPR (25$100 \mathrm{msec}$ (SI) in 11 experiments.

ity was a consequence of postsynaptic factors, presynaptic factors, or both, we plotted the ratio of the square of the coefficient of variation $\left(\mathrm{CV} ; \mathrm{CV}=\mathrm{SD} /\right.$ mean amplitude) for $\mathrm{EPSC}_{1}$ and $\mathrm{EPSC}_{2}$ against the ratio of the mean amplitudes of EPSC and EPSC $_{1}$ for a number of experiments (Fig. $1 D_{2}$ ). From binomial quantal statistics, points falling on or below the line of unity slope would indicate that PPD arises from purely presynaptic changes, whereas points above the line indicate that both presynaptic and postsynaptic changes in quantal transmission underlie PPD (Korn et al., 1984; Faber and Korn, 1991). In every case, data fell below the line with unity slope (Fig. $1 D_{2}$ ), indicating that the change in variability accompanying PPD could be explained entirely by presynaptic changes. There was no change in fiber excitability between the first and second pulse, because the amplitude of ON-evoked fiber volleys evoked by paired pulse stimulation were similar (data not shown). Together, these data indicate that paired pulse depression at synapses between ON fibers and their 
targets in the olfactory bulb is a consequence of changes in the amount of transmitter released.

At a variety of central synapses, manipulations that enhance transmitter release decrease the PPR, whereas inhibiting transmitter release increases the PPR (Zucker and Regehr, 2002). Thus, the PPR is often thought to reflect the underlying probability of transmitter release $\left(\mathrm{P}_{\mathrm{r}}\right)$ at nerve terminals. Synapses that show paired pulse facilitation are thought to have a relatively low $\mathrm{P}_{\mathrm{r}}$, whereas synapses that show PPD are thought to have a high $\mathrm{P}_{\mathrm{r}}$ (Dobrunz and Stevens, 1997). The large presynaptic paired pulse depression at $\mathrm{ON}$ synapses suggests that these synapses may have a high intrinsic $\mathrm{P}_{\mathrm{r}}$. To estimate the $\mathrm{P}_{\mathrm{r}}$ of glutamate from $\mathrm{ON}$ terminals, we first analyzed the rate at which the NMDAR open channel blocker MK-801 inhibited ON-evoked NMDAR EPSCs in PG neurons (Hessler et al., 1993; Rosenmund et al., 1993). After establishing a stable ON-evoked NMDAR response at +50 $\mathrm{mV}$ in the presence of NBQX, stimulation was stopped and MK$801(40 \mu \mathrm{M})$ bath-applied. After allowing $4 \mathrm{~min}$ for MK-801 to equilibrate at NMDARs in the slice, ON stimulation was then resumed. ON stimulation in the presence of MK-801 caused a rapid progressive block of the amplitude of NMDAR EPSCs (Fig. $2 A_{1}$ ). Consistent with the open channel-blocking action of MK801, NMDAR EPSCs in the presence of MK-801 exhibited much faster decay kinetics than under control conditions (Jahr, 1992) (Fig. 2 $\mathrm{A}_{2}$ ). The progressive block of NMDAR EPSCs was well fitted by a single exponential with a rate constant of $2.13 \pm 0.10$ episodes (Fig. $2 A_{3}$ ).

The rate of progressive blockade will depend not only on the $\mathrm{P}_{\mathrm{r}}$ but also the blocking rate of a given concentration of MK-801 at synaptic NMDARs. We used two approaches to determine the blocking rate of $40 \mu \mathrm{M}$ MK-801 at NMDARs under our recording conditions. First, we repeated the progressive block experiments using a brief focal application of glutamate (100 $\mu \mathrm{M} ; 10-20 \mathrm{msec})$ applied by puffer pipette in the presence of tetrodotoxin $(1 \mu \mathrm{M})$. This yielded NMDAR-mediated responses in PG cells (data not shown) that simulate glutamate released from a point source with a $\mathrm{P}_{\mathrm{r}}$ of 1 . The same concentration of MK-801 (40 $\left.\mu \mathrm{M}\right)$ caused a monoexponential progressive block of the amplitude of glutamate-evoked NMDAR responses with a rate of $0.89 \pm 0.05$ episodes (Fig. $2 \mathrm{~A}_{3}$ ), only slightly more rapid than the blockade of $\mathrm{ON}$-evoked EPSCs. The percentage of channels opened by glutamate that were blocked by $40 \mu \mathrm{M} \mathrm{MK}-801$ in a single episode can be determined by the amplitude reduction that occurred between the first and second episodes in the blocker $(0.70 \pm 0.07)$. Although this approach using exogenously applied glutamate yields an estimate of fractional block, it may not specifically address the properties of NMDARs at ON synapses. To address this concern, we used kinetic modeling of the effect of MK-801 on the time course of NMDAR EPSCs to determine the blocking rate of 40 $\mu \mathrm{M}$ MK-801 and the percentage of synaptic channels opened by glutamate that were blocked by MK-801 in a single trial [fraction blocked (FB); see Materials and Methods] (Hessler et al., 1993; Rosenmund et al., 1993; Huang and Stevens, 1997). To determine the percentage of synaptic channels opened by glutamate that were blocked by MK-801 in a single episode, EPSCs were simulated using fitted rate constants (Fig. $2 A_{3}$, inset) in the absence and presence of MK-801. The simulated EPSCs were integrated, and a ratio of total charge was used to determine FB. This approach yielded a value for $\mathrm{FB}$ of $0.61 \pm 0.05$, which agrees closely with the amount of inhibition produced by a single application of glutamate in the presence of MK-801 described above. Although this value for the FB of NMDARs by $40 \mu \mathrm{M}$ MK- 801 is higher than a previous report in cultured hippocampal neurons (Jahr, 1992),
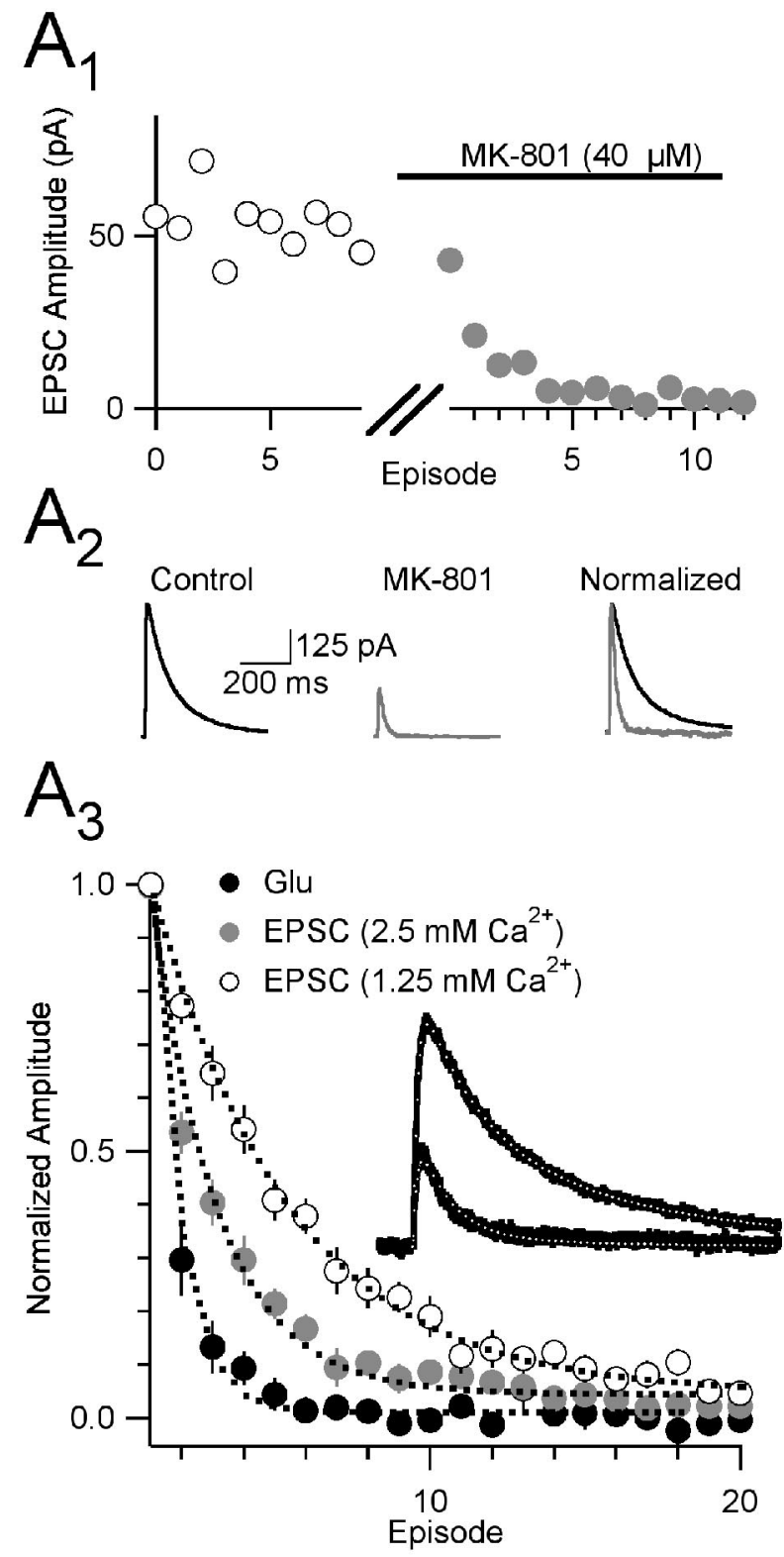

Figure 2. Progressive blockade of ON-evoked NMDAR EPSCs by MK-801 indicates $P_{r}$ from ON terminals is high. $A_{1}$, NMDAR EPSC amplitude versus episode number for a typical experiment. After establishing a stable ON-evoked NMDAR-mediated response (open circles), stimulation was halted, and MK-801 was introduced. In the presence of MK-801, the peak NMDAR EPSC amplitude (gray circles) declined rapidly when stimulation was resumed. $A_{2}$, Average response to $0 \mathrm{~N}$ stimulation before (control) and average of the first five responses in MK-801. $A_{3}$, NMDARmediated currents evoked by brief (15 msec) pressure application of glutamate (Glu; $100 \mu \mathrm{m}$ ) and ON stimulation in normal aCSF $\left(2.5 \mathrm{~mm} \mathrm{Ca}^{2+} ;\right.$ gray circles) or low $\mathrm{Ca}^{2+}(1.25 \mathrm{~mm}$; open circles) are inhibited progressively in the presence of MK-801 with a monoexponental time course $\left(\tau_{\text {glu }}=0.89\right.$ episodes; $\tau_{\text {EPSC } 2.5}=2.12$ episodes; $\tau_{\text {EPSC } 1.25}=4.7$ episodes). Inset, ON-evoked NMDAR-mediated currents under control conditions and in MK-801. White dots represent fits to the data generated by the kinetic model (see Materials and Methods).

it is identical to that derived from similar experiments performed in hippocampal slices (Huang and Stevens, 1997). Presumably, the hydrophobicity of MK-801 makes it difficult to achieve the same effective concentrations at synapses in brain slices compared with isolated neurons in culture. Once the FB of synaptic NMDARs is known, the $\mathrm{P}_{\mathrm{r}}$ can be determined by dividing the initial progressive blocking rate of the NMDAR EPSC (the amount of inhibition between the first and second stimulus in 
the presence of $\mathrm{MK}-801$ ) by the predicted blocking rate if $\mathrm{P}_{\mathrm{r}}=1$ (FB). In our experiments, the initial progressive blocking rate of ON-evoked NMDAR EPSCs $(0.47 \pm 0.04 ; n=14)$ and FB $(0.61)$ gives $\mathrm{P}_{\mathrm{r}}=0.77$.

Our experiments examining the progressive block of NMDAR EPSCs by MK-801 suggest that ON terminals release transmitter with a high probability $(\sim 0.8)$ after a presynaptic action potential. We next considered whether this technique could detect changes in transmitter release probability by repeating the experiments on ON-evoked EPSCs in the presence of a reduced concentration of extracellular calcium. Reducing extracellular $\mathrm{Ca}^{2+}$ from 2.5 to $1.25 \mathrm{~mm}$ to reduce $\mathrm{P}_{\mathrm{r}}$ decreased the amplitude of AMPAR EPSCs by $41 \pm 5 \%\left(n=8 ; 32^{\circ} \mathrm{C}\right)$. In a separate series of experiments, reducing extracellular $\mathrm{Ca}^{2+}$ to $1.25 \mathrm{~mm}$ slowed dramatically the rate of progressive blockade of NMDAR EPSCs by MK-801 (Fig. $2 A_{3}$ ). In $1.25 \mathrm{mM} \mathrm{Ca}^{2+}$, the initial progressive blocking rate $(0.23 \pm 0.03)$ (Fig. $\left.2 A_{3}\right)$ was almost exactly $50 \%$ of that observed under control conditions, whereas FB was unchanged $(0.63 \pm 0.05 ; n=5)$. These experiments suggest that the MK-801 technique can track changes in $\mathrm{P}_{\mathrm{r}}$ and independently demonstrate the validity of the approach as a measure of $\mathrm{P}_{\mathrm{r}}$ at $\mathrm{ON}$ terminals.

The value of $\mathrm{P}_{\mathrm{r}}$ determined from the progressive blocking rate of NMDARs by MK-801 will be underestimated if synaptic NMDARs are not saturated. To obtain an independent measure of $\mathrm{ON} \mathrm{P}_{\mathrm{r}}$, we used stationary fluctuation analysis of AMPAR EPSCs (Clements and Silver, 2000). The variance of ON-evoked EPSCs was determined under control conditions and then again after reducing $\mathrm{P}_{\mathrm{r}}$ by applying the $\mathrm{Ca}^{2+}$ channel blocker $\mathrm{Cd}^{2+}$. As expected for synapses with a high $\mathrm{P}_{\mathrm{r}}$, the variance of $\mathrm{ON}$-evoked EPSCs was very small under control conditions (Fig. $3 A$ ) and increased after application of $\mathrm{Cd}^{2+}$. In the presence of high concentrations of $\mathrm{Cd}^{2+}$, where transmission was inhibited by $>75 \%$, the variance was again small. Parabolic fits to the relationship between variance and mean EPSC amplitude indicated that the $\mathrm{P}_{\mathrm{r}}$ from ON terminals was $0.92 \pm 0.03(n=6)$ under control conditions. In five of the six experiments, there was good agreement between the quantal amplitude predicted from the variancemean relationship and the average amplitude of miniature EPSCs measured in the same cells (Fig. 3B). On average, the mean quantal amplitude predicted from the variance-mean relationships $(25.0 \pm 10 \mathrm{pA})$ was indistinguishable from the average amplitude of miniature EPSCs measured in the same cells $(21.9 \pm 4.3 \mathrm{pA}$; $p=0.66$ ) (Fig. $3 B$ ). The relatively close agreement between the measured and predicted quantal amplitude provides independent confirmation of this analytical approach. Together, the experiments examining the progressive blockade of ON-evoked NMDAR EPSCs by MK-801 and stationary fluctuation analysis of AMPAR EPSCs indicate that the $\mathrm{P}_{\mathrm{r}}$ from $\mathrm{ON}$ terminals is very high $(\geq 0.8)$.

Climbing fiber synapses in the cerebellum release glutamate with a high $\mathrm{P}_{\mathrm{r}}$ (Silver et al., 1998) and exhibit properties consistent with multivesicular release (Wadiche and Jahr, 2001). Do all CNS synapses with a high intrinsic $\mathrm{P}_{\mathrm{r}}$ exhibit signs of multivesicular release? To ask whether multivesicular release occurs at ON terminal synapses, we probed the sensitivity of ON transmission to low-affinity glutamate receptor antagonists under conditions of high and low $\mathrm{P}_{\mathrm{r}}$. If multivesicular release occurs at this synapse under control conditions, the concentration of glutamate in the synaptic cleft should be higher and transmission less sensitive to block by low-affinity competitive antagonists than when $\mathrm{P}_{\mathrm{r}}$ is lowered (Clements et al., 1992; Tong and Jahr, 1994). We first examined the action of the low-affinity antagonist
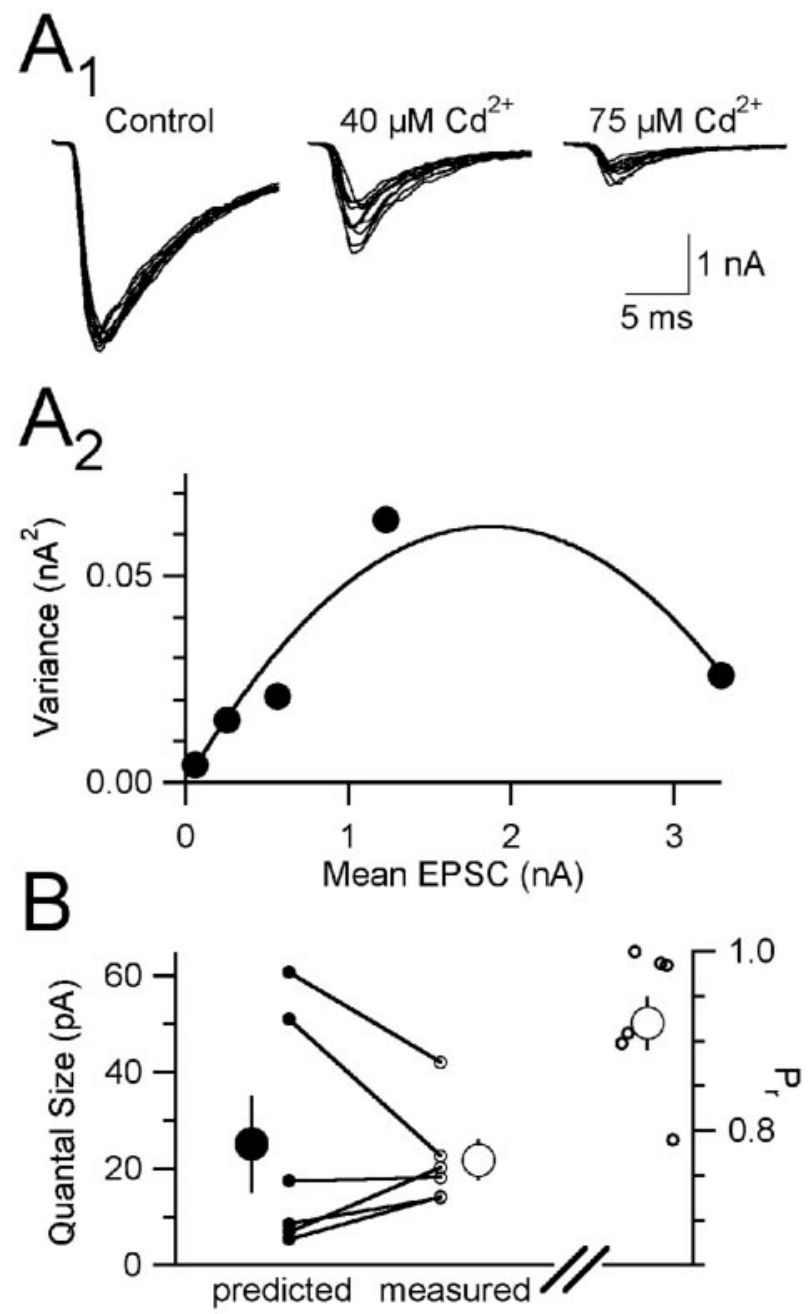

Figure 3. Nonstationary fluctuation analysis of ON-evoked AMPAR-mediated EPSCs indicates $P_{r}$ from $0 N$ terminals is high. $A_{1}$, Ten consecutive $0 \mathrm{~N}$-evoked EPSCs under control conditions and in the presence of two different concentrations of $\mathrm{Cd}^{2+} . A_{2}$, Variance-mean plot for the representative experiment in $A_{1}$. The estimated $P_{r}$ in this experiment is 0.96 . $B$, The predicted (small closed circle) and measured (small open circle) quantal size for each experiment. The average predicted (large filled circle) and measured (large open circle) quantal sizes were not significantly different ( $p=0.66$; left axis). $P_{r}$ for each of the six individual experiments (small open circles) and the average estimated for the population (large open circle) are plotted on the right axis.

$\gamma$-DGG (2 mm) on the peak amplitude of ON-evoked AMPARmediated EPSCs evoked by paired pulse stimulation (interstimulus interval, $25 \mathrm{msec}$ ) in PG cells. Under control conditions of high $\mathrm{P}_{\mathrm{r}}\left(2.5 \mathrm{mM} \mathrm{Ca}{ }^{2+}\right.$; PPR $\left.=0.44 \pm 0.04\right), \gamma$-DGG blocked EPSC $_{1}$ by $51 \pm 4 \%(n=12)$. In cells recorded in low extracellular calcium to reduce $\mathrm{P}_{\mathrm{r}}\left(0.5 \mathrm{mM} \mathrm{Ca}^{2+} ; \mathrm{PPR}=1.53 \pm 0.14\right)$ (Fig. $4 A$ ), $\gamma$-DGG blocked EPSC 1 to the same extent (56 $\pm 5 \% ; n=$ 10). Similarly, $\gamma$-DGG blocked EPSC $_{2}$ by the same amount under conditions of strong paired pulse facilitation or depression (Fig. $4 A$ ). NBQX (250 nM), a high-affinity AMPAR antagonist, also inhibited ON-evoked EPSCs equally in $2.5(69 \pm 4 \% ; n=11)$ and $0.5 \mathrm{mM} \mathrm{Ca}^{2+}(69 \pm 6 \% ; n=7)$. We next examined the actions of a low-affinity competitive antagonist on transmission mediated by NMDARs. Like the low-affinity AMPAR antagonist, a lowaffinity competitive antagonist of NMDARs (L-APV; $1 \mathrm{~mm}$ ) blocked ON-evoked NMDAR EPSCs to the same extent under control conditions $(61 \pm 4 \% ; n=4)$ and when $\mathrm{P}_{\mathrm{r}}$ had been reduced ( $56 \pm 6 \% ; n=6$ ) (Fig. $4 B$ ). Together, these experiments 

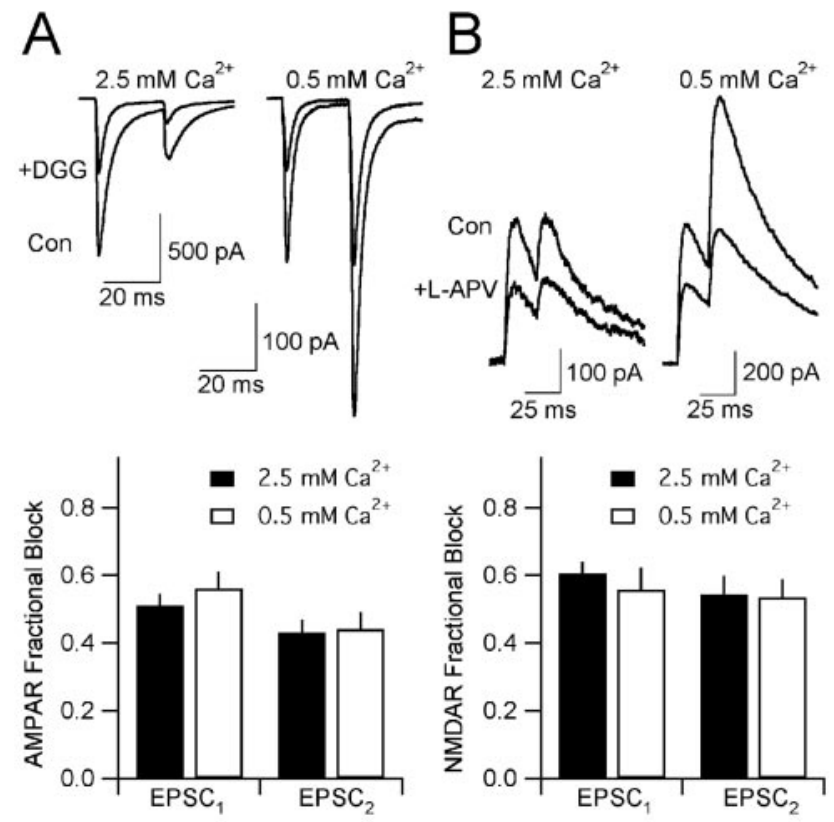

Figure 4. ON-evoked EPSCs are equally sensitive to low-affinity glutamate receptor antagonists under conditions of high or low $P_{r} . A, \gamma$-DGG $(2 \mathrm{~mm})$ blocks AMPAR-mediated EPSCs to the

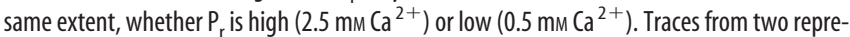
sentative experiments are shown above; the average fractional block of $\mathrm{EPSC}_{1}$ and $\mathrm{EPSC}_{2}$ by $\gamma$-DGG when $P_{r}$ is high $(n=12)$ and low $(n=10)$ shown below was indistinguishable $(p>$ 0.6). B, L-APV (1 mM) inhibits NMDAR-mediated EPSCs evoked by ON stimulation to the same degree when $P_{r}$ is high and low $(n=5 ; p>0.5)$.

using low-affinity receptor antagonists indicate that the concentration of glutamate at $\mathrm{ON}$ synapses does not change when $\mathrm{P}_{\mathrm{r}}$ is varied. These findings suggest that although $\mathrm{ON}$ synapses have a high intrinsic $\mathrm{P}_{\mathrm{r}}$, they do not show evidence of multivesicular release.

To further examine the nature of transmitter release from $\mathrm{ON}$ terminals, we explored the relationship between glutamate release and extracellular $\mathrm{Ca}^{2+}$. At most synapses, this relationship is highly nonlinear (Dodge and Rahamimoff, 1967; Augustine et al., 1985; Mintz et al., 1995; Borst and Sakmann, 1996; Reid et al., 1998; Stevens and Sullivan, 2003) and is well fit by a Hill equation with a cooperativity coefficient between three and four. The nonlinear dependence of transmission on extracellular $\mathrm{Ca}^{2+}$ is thought to reflect the cooperative binding of $\mathrm{Ca}^{2+}$ ions to the $\mathrm{Ca}^{2+}$ sensor that underlies release (Stevens, 2003). We used recordings of glomerular field EPSPs as well as AMPAR EPSCs in voltage-clamped PG cells (at room temperature) to record changes in synaptic strength under conditions of varying extracellular calcium. Responses were normalized to the amplitude under control conditions $\left(2.5 \mathrm{mM} \mathrm{Ca}^{2+}\right)$ and were plotted on a $\log -\log$ graph (Fig. 5A). The results using the peak amplitude of the fEPSP (Fig. $5 A$, closed circles) were in close agreement with measurements of the EPSC amplitude (Fig. 5A, open circles). Unlike most conventional nerve terminals, the relationship between release from ON terminals and extracellular $\mathrm{Ca}^{2+}$ was well fit by a Hill equation with a cooperativity coefficient of $n=1.52$ (Fig. $5 A_{2}$ ). To determine whether the low $\mathrm{Ca}^{2+}$ cooperativity is a general feature of transmission in the olfactory system, we examined the $\mathrm{Ca}^{2+}$ dependence of transmission between the axons of $\mathrm{M} / \mathrm{T}$ cells and pyramidal cell dendrites in the piriform cortex. Transmission at these synapses exhibited more typical $\mathrm{Ca}^{2+} \mathrm{CO}-$ operativity (coefficient, $n=3.23$ ) (Fig. 5B). Thus, glutamate release from $\mathrm{ON}$ terminals is not nearly as steeply dependent on extracellular $\mathrm{Ca}^{2+}$ compared with other brain synapses.

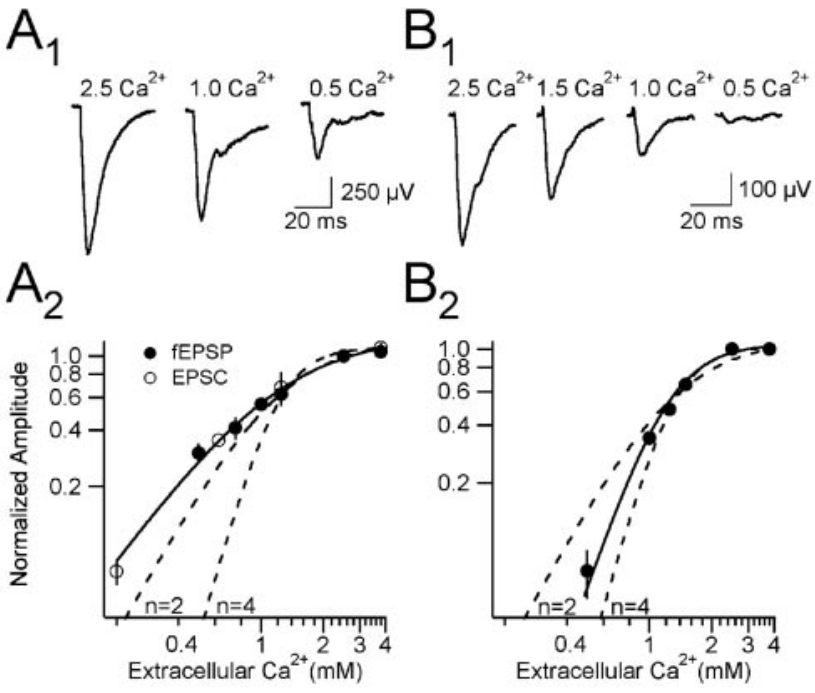

Figure 5. ON transmitter release exhibits unusual $\mathrm{Ca}^{2+}$ cooperativity. $A_{1}, 0 \mathrm{~N}$-evoked glomerular fEPSPs from a representative experiment in normal $(2.5 \mathrm{~mm})$ and reduced $\mathrm{Ca}^{2+} . A_{2}$, Normalized amplitude of ON-evoked glomerular fEPSPs (filled circles) and AMPAR-mediated EPSCs (open circles) as a function of extracellular $\mathrm{Ca}^{2+}$. Each point represents the average of three to six experiments. Predicted relationships for data with an identical $K_{0.5}(1.19)$ and cooperativity $(n)$ values of 2 and 4 are shown as dashed lines. $B_{1}$, LOT-evoked fEPSPs in piriform cortex from a representative experiment in normal (2.5) and reduced $\mathrm{Ca}^{2+}$ aCSF. $B_{2}$, Normalized amplitude of LOT-evoked fEPSPs; predicted relationships for $n=2$ and 4 are shown as in $A_{2}$, with $K_{0.5}=1.28$. All experiments in this figure were performed at room temperature.

\section{Discussion}

Synaptic transmission at conventional glutamatergic nerve terminals in the brain is generally unreliable, with the probability of an action potential evoking transmitter release $\ll 1$. Sensory neurons in the retina and cochlea have presynaptic specializations that enable high fidelity transmission of sensory information (Lenzi and von Gersdorff, 2001). In contrast, olfactory receptor neurons project directly to the brain and make conventional nerve endings (Pinching and Powell, 1971; White, 1972, 1973). In this study, we explored the fundamental features of transmitter release from olfactory nerve terminals in the olfactory bulb. We show that strong paired pulse depression is an intrinsic feature of olfactory nerve terminals. We used several independent methods to show that the probability of release from olfactory nerve terminals is unusually high. Despite having a high probability of release, olfactory nerve terminals do not show evidence of multivesicular release. We also demonstrate that transmission from olfactory nerve terminals is unusual in that the relationship between transmitter release and extracellular $\mathrm{Ca}^{2+}$ is nearly linear.

We found that ON terminals show marked PPD at two distinct postsynaptic targets in olfactory bulb glomeruli: principal tufted cells and local interneurons, the periglomerular cells. The similar degree of PPD at these two targets strongly suggests that PPD is an intrinsic feature of glutamate release from ON terminals. The lack of an effect of cyclothiazide on the PPR of ONevoked responses is consistent with the idea that AMPAR desensitization does not underlie PPD. Moreover, the AMPA and NMDA receptor-mediated components of transmission at $\mathrm{ON}$ synapses showed nearly identical PPD, unlike other synapses in the CNS, in which AMPAR desensitization contributes to shortterm plasticity (Trussell et al., 1993; Chen et al., 2002).

One might predict that NMDAR responses would exhibit more PPD than AMPAR responses at ON synapses, because NMDARs should be more readily saturated by synaptically re- 
leased glutamate. According to this logic, there should be fewer available NMDARs able to respond to glutamate released by the second (test) stimulus, because a sizeable fraction of synaptic NMDARs is still bound by glutamate from the first (conditioning) stimulus. One possibility is that both AMPA and NMDARs at $\mathrm{ON}$ synapses are so far from saturation that glutamate release evoked by the first stimulus does not significantly decrease the number of receptors available to be bound by glutamate released during the second stimulus. However, the rapid progressive block of ON NMDAR EPSCs by MK-801 suggests that synaptic NMDARs must be relatively close to saturation when transmitter is released from an ON terminal. One possible explanation for the identical PPR of AMPAR and NMDAR EPSCs is that synapses that release transmitter in response to the first stimulus do not release transmitter during the second stimulus at interstimulus intervals $\leq 100 \mathrm{msec}$. This refractory period might reflect the time it takes to prime another vesicle for release from ON terminals.

Variance analysis indicated that the differences in variability of responses evoked by paired pulse stimulation could be accounted for entirely by presynaptic changes, although we cannot distinguish between a reduction in the number of release sites and a reduction in $\mathrm{P}_{\mathrm{r}}$ as the mechanism underlying PPD. The strong presynaptic $\mathrm{PPD}$ of $\mathrm{ON}$ transmission suggested to us that the intrinsic probability of release at ON terminals is high. Indeed, quantitative analysis of the progressive block of NMDAR EPSCs by $\mathrm{MK}-801$ indicated a $\mathrm{P}_{\mathrm{r}}$ of $\sim 0.8$. Olfactory receptor neurons are replaced every few weeks (Schwob, 2002) so the identity of cells providing synaptic input to the olfactory bulb is constantly in flux. Might $\mathrm{P}_{\mathrm{r}}$ or other characteristics of $\mathrm{ON}$ synaptic transmission be different at newly formed terminals? The progressive block of ON-evoked responses by MK-801 was well fitted by a single exponential, indicating that the population of $\mathrm{ON}$ terminals has a rather uniform distribution of release probabilities. However, it is possible that the proportion of synaptic transmission contributed by recently established $\mathrm{ON}$ terminals is too small to be resolved relative to that from more mature synaptic contacts. Alternatively, there may not yet be appreciable regeneration of ORNs over the age range (2-3 postnatal weeks) examined in our study.

Estimating the $\mathrm{P}_{\mathrm{r}}$ of ON terminals from the progressive blocking rate of MK-801 generally assumes that synaptic NMDARs are close to saturation by synaptically released glutamate (Hessler et al., 1993; Rosenmund et al., 1993). However, recent studies of hippocampal synapses suggest that NMDARs may not be saturated during a single release event (Mainen et al., 1999; McAllister and Stevens, 2000). Furthermore, MK-801 blocking experiments could overestimate $\mathrm{P}_{\mathrm{r}}$ if glutamate spillover from multiple neighboring synapses contributes to the peak amplitude of evoked NMDAR EPSCs. Although we think it is unlikely that these scenarios apply at ON synapses, we used stationary fluctuation analysis of AMPAR EPSCs (Clements and Silver, 2000) to derive a measure of release probability from ON terminals that is independent of assumptions regarding the properties of synaptic NMDARs. In agreement with our previous measure of $\mathrm{P}_{\mathrm{r}}$, this approach yielded an average $\mathrm{P}_{\mathrm{r}}$ close to 1 .

It has been suggested in several systems that the peak concentration of glutamate in the synaptic cleft $\left(\mathrm{cleft}_{[\mathrm{glu}]}\right)$ can be sensitive to the $\mathrm{P}_{\mathrm{r}}$ (Tong and Jahr, 1994; Wadiche and Jahr, 2001). The best evidence supporting a change in cleft $\mathrm{fglu}_{\text {[lu }}$ is that competitive low-affinity glutamate receptor antagonists block transmission to a greater extent when $\mathrm{P}_{\mathrm{r}}$ is lowered. These data have been interpreted to mean that multivesicular release can occur at individual synapses and have led to suggestions that multivesicular release might be a general feature of high $\mathrm{P}_{\mathrm{r}}$ synapses (Tong and Jahr, 1994;
Wadiche and Jahr, 2001). Although the $\mathrm{P}_{\mathrm{r}}$ from ON terminals is unusually high, we did not see any obvious changes in the sensitivity of either NMDAR- or AMPAR-mediated synaptic transmission to low-affinity receptor antagonists under conditions of low and high $\mathrm{P}_{\mathrm{r}}$. Our results are very similar to those reported recently at synapses between layer 4 and 2/3 neurons in barrel cortex. Like ON terminals, layer 4 neurons release transmitter with a high probability $(\sim 0.8)$, and cleft ${ }_{[\mathrm{glu}]}$ is independent of $\mathrm{P}_{\mathrm{r}}$ (Silver et al., 2003). Together, these data do not support the idea that the peak cleft ${ }_{[\mathrm{glu}]}$ varies as a function of $\mathrm{P}_{\mathrm{r}}$ at all central synapses, although they do not rule out the possibility that spillover and pooling of transmitter can occur during the decaying phase of synaptic responses.

An intriguing finding in our study is that $\mathrm{ON}$ terminals show a relatively linear relationship to extracellular $\mathrm{Ca}^{2+}$. Could our measurement of the relationship between calcium and $\mathrm{ON}$ transmitter release be complicated by other factors? In our calcium dose-response experiments, we substituted $\mathrm{Mg}^{2+}$ in place of $\mathrm{Ca}^{2+}$ to keep the concentration of divalent cations constant. Theoretically, because we alter the calcium/magnesium ratio, one interpretation is that the magnesium sensitivity of release at $\mathrm{ON}$ terminals is unusual. However, a role for magnesium in the cooperativity of release has not been established. The most parsimonious interpretation of our data is that the calcium sensitivity of release appears different in the olfactory bulb. Reducing the concentration of extracellular $\mathrm{Ca}^{2+}$ from 2.5 to $1.25 \mathrm{~mm}$ reduced the rate of progressive blockade of NMDAR EPSCs by MK- 801 by $47 \%$. This is similar to the reduction in synaptic transmission determined from the $\mathrm{Ca}^{2+}$ response relationship using AMPARmediated synaptic responses $(\sim 40 \%)$. Altogether, our data suggest that the unusually shallow dependence of release on $\mathrm{Ca}^{2+}$ is not a consequence of postsynaptic receptor saturation or multivesicular release at $\mathrm{ON}$ synapses. Although the cooperativity between release and $\mathrm{Ca}^{2+}$ was unusual at $\mathrm{ON}$ synapses, the concentration of extracellular $\mathrm{Ca}^{2+}$ at which transmission was half maximal was the same $\left(K_{0.5}, \sim 1.2 \mathrm{~mm}\right)$ at $\mathrm{ON}$ synapses and the synaptic contacts formed by olfactory bulb principal cells in the piriform cortex. These data raise the possibility that $\mathrm{Ca}^{2+}$ dependent release from $\mathrm{ON}$ terminals relies on an atypical form of synaptotagmin that exhibits relatively normal $\mathrm{Ca}^{2+}$ dependence but altered $\mathrm{Ca}^{2+}$ cooperativity. Synaptotagmin IV represents a possible candidate, because it is present in olfactory bulb glomeruli and can regulate the efficacy of transmission (Berton et al., 1997; Littleton et al., 1999).

What might be the consequences of these intrinsic features of ON transmitter release for olfaction? From a purely anatomical perspective, the massive glomerular-specific convergence of axons from ORNs that detect the same molecular features of an odorant are one way to increase the efficiency of activating principal M/T cells. Our data suggest that the $\mathrm{P}_{\mathrm{r}}$ from $\mathrm{ON}$ terminals is likely near maximal when odorants evoke action potentials at a relatively low frequency in ORNs. This would serve to ensure transmission of information contained in the sparse firing of olfactory receptor neurons activated by threshold odorant concentrations. In contrast, strong paired pulse depression likely constrains the saliency of bursts evoked by high concentrations of odorant to the first spike. PG cells are thought to release dopamine and GABA in olfactory bulb glomeruli (McLean and Shipley, 1988; Smith and Jahr, 2002). These local neuromodulators, which lower $\mathrm{P}_{\mathrm{r}}$ and reduce paired pulse depression via activation of presynaptic $\mathrm{GABA}_{\mathrm{B}}$ and $\mathrm{D}_{2}$ receptors (Aroniadou-Anderjaska et al., 2000; Ennis et al., 2001), could further shape the dynamic range of ORN input to the bulb in vivo. 


\section{References}

Aroniadou-Anderjaska V, Zhou FM, Priest CA, Ennis M, Shipley MT (2000) Tonic and synaptically evoked presynaptic inhibition of sensory input to the rat olfactory bulb via GABA(B) heteroreceptors. J Neurophysiol 84:1194-1203.

Augustine GJ, Charlton MP, Smith SJ (1985) Calcium entry and transmitter release at voltage-clamped nerve terminals of squid. J Physiol (Lond) 367:163-181.

Bellingham MC, Walmsley B (1999) A novel presynaptic inhibitory mechanism underlies paired pulse depression at a fast central synapse. Neuron 23:159-170.

Berton F, Iborra C, Boudier JA, Seagar MJ, Marqueze B (1997) Developmental regulation of synaptotagmin I, II, III, and IV mRNAs in the rat CNS. J Neurosci 17:1206-1216.

Borst JG, Sakmann B (1996) Calcium influx and transmitter release in a fast CNS synapse. Nature 383:431-434.

Chen C, Blitz DM, Regehr WG (2002) Contributions of receptor desensitization and saturation to plasticity at the retinogeniculate synapse. Neuron 33:779-788.

Chess A, Simon I, Cedar H, Axel R (1994) Allelic inactivation regulates olfactory receptor gene expression. Cell 78:823-834.

Clements JD, Silver RA (2000) Unveiling synaptic plasticity: a new graphical and analytical approach. Trends Neurosci 23:105-113.

Clements JD, Lester RA, Tong G, Jahr CE, Westbrook GL (1992) The time course of glutamate in the synaptic cleft. Science 258:1498-1501.

Diamond JS, Jahr CE (1995) Asynchronous release of synaptic vesicles determines the time course of the AMPA receptor-mediated EPSC. Neuron 15:1097-1107.

Dobrunz LE, Stevens CF (1997) Heterogeneity of release probability, facilitation, and depletion at central synapses. Neuron 18:995-1008.

Dodge Jr FA, Rahamimoff R (1967) Co-operative action a calcium ions in transmitter release at the neuromuscular junction. J Physiol (Lond) 193:419-432.

Ennis M, Zhou FM, Ciombor KJ, Aroniadou-Anderjaska V, Hayar A, Borrelli E, Zimmer LA, Margolis F, Shipley MT (2001) Dopamine D2 receptormediated presynaptic inhibition of olfactory nerve terminals. J Neurophysiol 86:2986-2997.

Faber DS, Korn H (1991) Applicability of the coefficient of variation method for analyzing synaptic plasticity. Biophys J 60:1288-1294.

Firestein S (2001) How the olfactory system makes sense of scents. Nature 413:211-218.

Hessler NA, Shirke AM, Malinow R (1993) The probability of transmitter release at a mammalian central synapse. Nature 366:569-572.

Huang EP, Stevens CF (1997) Estimating the distribution of synaptic reliabilities. J Neurophysiol 78:2870-2880.

Jahr CE (1992) High probability opening of NMDA receptor channels by L-glutamate. Science 255:470-472.

Juusola M, French AS, Uusitalo RO, Weckstrom M (1996) Information processing by graded-potential transmission through tonically active synapses. Trends Neurosci 19:292-297.

Korn H, Faber DS, Burnod Y, Triller A (1984) Regulation of efficacy at central synapses. J Neurosci 4:125-130.

Laughlin SB, de Ruyter van Steveninck RR, Anderson JC (1998) The metabolic cost of neural information. Nat Neurosci 1:36-41.

Lenzi D, von Gersdorff H (2001) Structure suggests function: the case for synaptic ribbons as exocytotic nanomachines. BioEssays 23:831-840.

Littleton JT, Serano TL, Rubin GM, Ganetzky B, Chapman ER (1999) Synaptic function modulated by changes in the ratio of synaptotagmin I and IV. Nature 400:757-760.

Mainen ZF, Malinow R, Svoboda K (1999) Synaptic calcium transients in single spines indicate that NMDA receptors are not saturated. Nature 399:151-155.

McAllister AK, Stevens CF (2000) Nonsaturation of AMPA and NMDA receptors at hippocampal synapses. Proc Natl Acad Sci USA 97:6173-6178.

McLean JH, Shipley MT (1988) Postmitotic, postmigrational expression of tyrosine hydroxylase in olfactory bulb dopaminergic neurons. J Neurosci 8:3658-3669.

Mennerick S, Zorumski CF (1996) Postsynaptic modulation of NMDA synaptic currents in rat hippocampal microcultures by paired-pulse stimulation. J Physiol (Lond) 490:405-407.

Mintz IM, Sabatini BL, Regehr WG (1995) Calcium control of transmitter release at a cerebellar synapse. Neuron 15:675-688.
Mombaerts P, Wang F, Dulac C, Chao SK, Nemes A, Mendelsohn M, Edmondson J, Axel R (1996) Visualizing an olfactory sensory map. Cell 87:675-686.

Mori K, Nagao H, Yoshihara Y (1999) The olfactory bulb: coding and processing of odor molecule information. Science 286:711-715.

Murphy GJ, Isaacson JS (2003) Presynaptic cyclic nucleotide-gated ion channels modulate neurotransmission in the mammalian olfactory bulb. Neuron 37:639-647.

Nakamura T, Gold GH (1987) A cyclic nucleotide-gated conductance in olfactory receptor cilia. Nature 325:442-444.

Perkel DJ, Nicoll RA (1993) Evidence for all-or-none regulation of neurotransmitter release: implications for long-term potentiation. J Physiol (Lond) 471:481-500.

Pinching AJ, Powell TP (1971) The neuropil of the glomeruli of the olfactory bulb. J Cell Sci 9:347-377.

Reid CA, Bekkers JM, Clements JD (1998) N- and P/Q-type $\mathrm{Ca}^{2+}$ channels mediate transmitter release with a similar cooperativity at rat hippocampal autapses. J Neurosci 18:2849-2855.

Rosenmund C, Clements JD, Westbrook GL (1993) Nonuniform probability of glutamate release at a hippocampal synapse. Science 262:754-757.

Rubin BD, Katz LC (1999) Optical imaging of odorant representations in the mammalian olfactory bulb. Neuron 23:499-511.

Schwob JE (2002) Neural regeneration and the peripheral olfactory system. Anat Rec 269:33-49.

Serizawa S, Ishii T, Nakatani H, Tsuboi A, Nagawa F, Asano M, Sudo K, Sakagami J, Sakano H, Ijiri T, Matsuda Y, Suzuki M, Yamamori T, Iwakura Y (2000) Mutually exclusive expression of odorant receptor transgenes. Nat Neurosci 3:687-693.

Serizawa S, Miyamichi K, Nakatani H, Suzuki M, Saito M, Yoshihara Y, Sakano H (2003) Negative feedback regulation ensures the one receptor-one olfactory neuron rule in mouse. Science 302:2088-2094.

Silver RA, Momiyama A, Cull-Candy SG (1998) Locus of frequencydependent depression identified with multiple-probability fluctuation analysis at rat climbing fibre-Purkinje cell synapses. J Physiol (Lond) 510:881-902.

Silver RA, Lubke J, Sakmann B, Feldmeyer D (2003) High-probability uniquantal transmission at excitatory synapses in barrel cortex. Science 302: 1981-1984.

Smith TC, Jahr CE (2002) Self-inhibition of olfactory bulb neurons. Nat Neurosci 5:760-766.

Stevens CF (2003) Neurotransmitter release at central synapses. Neuron 40:381-388.

Stevens CF, Sullivan JM (2003) The synaptotagmin C2A domain is part of the calcium sensor controlling fast synaptic transmission. Neuron 39:299-308.

Stopfer M, Bhagavan S, Smith BH, Laurent G (1997) Impaired odour discrimination on desynchronization of odour-encoding neural assemblies. Nature 390:70-74.

Stopfer M, Jayaraman V, Laurent G (2003) Intensity versus identity coding in an olfactory system. Neuron 39:991-1004.

Tong G, Jahr CE (1994) Multivesicular release from excitatory synapses of cultured hippocampal neurons. Neuron 12:51-59.

Trussell LO, Zhang S, Raman IM (1993) Desensitization of AMPA receptors upon multiquantal neurotransmitter release. Neuron 10:1185-1196.

Vyklicky Jr L, Patneau DK, Mayer ML (1991) Modulation of excitatory synaptic transmission by drugs that reduce desensitization at AMPA/kainate receptors. Neuron 7:971-984.

Wachowiak M, Cohen LB (2001) Representation of odorants by receptor neuron input to the mouse olfactory bulb. Neuron 32:723-735.

Wadiche JI, Jahr CE (2001) Multivesicular release at climbing fiberPurkinje cell synapses. Neuron 32:301-313.

White EL (1972) Synaptic organization in the olfactory glomerulus of the mouse. Brain Res 37:69-80.

White EL (1973) Synaptic organization of the mammalian olfactory glomerulus: new findings including an intraspecific variation. Brain Res 60:299-313.

Yamada KA, Tang CM (1993) Benzothiadiazides inhibit rapid glutamate receptor desensitization and enhance glutamatergic synaptic currents. J Neurosci 13:3904-3915.

Zucker RS, Regehr WG (2002) Short-term synaptic plasticity. Annu Rev Physiol 64:355-405. 